\title{
Social Media as a Tool of Knowledge Sharing in Academia: An Empirical Study using Valance, Instrumentality and Expectancy (VIE) Approach
}

\author{
Sheshadri Chatterjee \\ Department of Computer Science \& Engineering \\ Indian Institute of Technology Kharagpur, India \\ Email: sheshadri.academic@gmail.com \\ Nripendra P. Rana* \\ School of Management, University of Bradford, Richmond Road, Bradford, BD7 1DP, UK \\ Email: nrananp@gmail.com \\ Yogesh K. Dwivedi \\ School of Management, Swansea University, Fabian Way, Swansea, SA1 8EN, UK \\ Email: ykdwivedi@gmail.com
}

\begin{abstract}
Purpose - The purpose of this paper is to understand the factors that determine the knowledge exchange intention and behavioural nature of academics by the help of social media tools in the Indian higher education.

Design/Methodology/Approach - This study has used Valance - Instrumentality Expectancy (VIE) theory to determine the knowledge exchange behaviour of academics. The study has considered the effect of Knowledge Contributor (KC) and Knowledge Seeker (KS) as moderators. The model has been validated by using a survey with 320 usable respondents.

Findings - The results highlight that if the stakeholders of higher education institutions feel the deficits of knowledge exchange, they realise importance of knowledge sharing and use social media to increase effect of knowledge exchange. Besides, perceived usefulness impacts on the use of social media for knowledge exchange by the concerned stakeholders. Moreover, it is observed that experience of the use of social media impacts the use of this tool for knowledge exchange.

Theoretical Implication - The use and application of VIE theory has successfully been able to interpret the factors affecting the use of social media for knowledge exchange in the higher education institutions. The use of VIE theory has also been able to explain the proposed model better as the model could achieve a high explanative power $(87 \%)$.

Practical Implication - This study has provided meaningful insights to the practitioners or policymakers to realise how the stakeholders of the higher education institutions in India can be motivated to feel the need of sharing of knowledge and how they can use the social media with ease for this purpose.

Originality/Value - Not much research has been conducted with regards to the usage of social media as a tool for knowledge sharing in higher education sector in India. In that sense, this study is a novel attempt to undertake such research.
\end{abstract}

Keywords - Social Media, Knowledge Contributor, Knowledge Seeker, Knowledge Sharing, VIE Approach, Academia

Paper Type - Research Paper 


\section{Social Media as a Tool of Knowledge Sharing in Academia: An Empirical Study Using Valance, Instrumentality and Expectancy (VIE) Approach}

\section{Introduction}

For ensuring success in any type of organization including business organizations, educational organizations, non-government organizations (NGOs), managing knowledge has become one of the most important strategic challenges. Knowledge management can be improved if there is possibility of effective knowledge sharing among the stakeholders of organizations (Venkitachalam and Busch, 2012; Chatterjee et al., 2020). In this context, the role of social media is vital. Social media is an effective instrument to transfer knowledge (Whittington, 2012). The applications of social media can be conceptualized through different parameters (Seitz and Misra, 2020). The parameters can be briefly classified as social networking sites (SNS) such as Facebook through which the academics can exchange their knowledge. Instant messaging application platforms such as WhatsApp, which is useful for real-time knowledge sharing by the academic stakeholders using text, pictures and so on. The academic stakeholders can also use different web applications for retrieving, traversing, and presenting information as per their requirements (Giunchiglia et al., 2018). With the help of these parameters, the stakeholders of higher institutions can easily exchange their information, knowledge-content and other academic issues in a swift and cost effective manner (Seitz and Misra, 2020). In the last few years, a considerable number of organizations have used social media to meaningfully facilitate knowledge sharing among their stakeholders (Pfisterer, Streim and Hampe, 2013; Bughin and Chui, 2013). So far as the educational organizations are concerned (especially higher education institutions), knowledge sharing among the students, the faculties and between students and faculties is expected to fetch better result (Grace, 2009; Goswami and Agrawal, 2019; Seitz and Misra, 2020). This exchange of knowledge among the stakeholders of the higher education institutions would be facilitated if it is done by the help of social media 
(Moskaliuk et al., 2009; Giudice et al., 2016). Stakeholders of higher education institutions are students, faculties, and administrative staff. Motivation for the stakeholders of higher education institutions is an important factor that derives the stakeholders to use social media for knowledge sharing. This motivation could be of two types - intrinsic motivation and extrinsic motivation (Deci and Ryan, 2000). The concept of motivation is needed to be realized in explaining the use of social media for knowledge sharing by the stakeholders of the higher education institutions.

If the faculties and the students feel that the use of social media tools would help for effective knowledge exchange, they would ensure the frequent use of social media for this purpose (Li, 2011; Yi, 2019; Rahmi and Indarti, 2019). It is important to gauge how the knowledge gained by the organization is being utilized. An organization would be able to develop its performance if it can utilize its knowledge repository in an efficient way (Haas and Hansen, 2005). Hence, accumulation of knowledge is essential, but it would not derive effective benefits to the organization if the knowledge is not shared for execution of knowledge-based strategies. Here is the need of knowledge sharing, which would help the organization for better execution of its knowledge-based strategies (Felin and Hesterly, 2007; Rahmi and Indarti, 2019). So far as the higher educational institutions are concerned; the students, the faculties, and even the administrative staff are required to share different types of knowledge. For example, if two faculties of two different educational institutions intend to discuss about a particular area of interest, they are required to interact with each other for exchange of knowledge to enrich the quality. If they use social media for interaction, it would be open for other interested individuals to take part in that discussion. It would improve the quality more. Exchange of knowledge through other means, except through social media, would confine the interactions between individuals. 
Similarly, among the students, say, for their project works, the contribution of usage of social media would enrich their works more in the same way. For the administrative staff of the educational institutions, use of social media also helps to contribute a lot. For example, if an educational institution intends to open a new course, the concerned administrative officials can conveniently discuss the matter with officials of other institutions where that course has already been running. It would help to know the pros and cons that might have to be faced while running the course. If these interactions are done through social media platform, other interested individuals can provide inputs and can share their experiences, which would provide invaluable inputs to the concerned educational institutions. In this way through social media, interactions on different issues of interest may be conducted across faculties and teachers, faculties and administrative staff and students and administrative staff for their improvement (Charband and Jafari, 2018; Linzalone et al., 2020). In this context, it is important to emphasize that only gaining knowledge will not suffice the purpose, but it is to be shared with others. Hence, for knowledge sharing, the parts played by the Knowledge Contributors (KCs) and Knowledge Seekers (KSs) for soothing flow of knowledge are important. Sharing of knowledge among the stakeholders of the higher education institutions through social media would enrich their depth of knowledge (Della Peruta et al., 2014).

In the Indian context, it is observed that the faculties and the students are not convinced about the advantages of social media for knowledge exchange (Pirkkalainen and Pawlowski, 2014). In some cases, it is experienced that they resist the use of social media for knowledge sharing (Preece and Shneiderman, 2009; Rahmi and Indarti, 2019; Goswami and Agarwal, 2019). This is due to lack of essential motivation among the faculties and students and this may be improved by effective cross-cultural management (Giudice et al., 2012). There are only handful of studies on knowledge exchange and management of knowledge in the higher education context (Fullwood et al., 2013). However, studies covering how such knowledge exchange in the higher 
education institutions can be improved using social media has remained under-explored. Besides, some recent studies have focussed on how certain factors can interpret behaviour of knowledge sharing among academics (Goh and Sandhu, 2013; Jolaee et al., 2014; Chong et al., 2014). Therefore, the following basic research questions (RQs) are raised through this research are as follows:

RQ1: What is the impact of 'knowledge contributor' and 'knowledge seeker' on intention to use social media for knowledge sharing in higher educational institutions? RQ2: Whether experienced social media users use social media more as a tool for knowledge sharing in higher educational institutions?

RQ3: Whether importance of knowledge exchange has influence on intention to use social media for knowledge sharing in higher education system?

The two factors $\mathrm{KC}$ and $\mathrm{KS}$ are perceived to act as moderators to influence the intention to use social media for knowledge sharing in academia. Hence, there is need to identify antecedents of stakeholders of the higher educational institutions to intend to use social media for knowledge sharing. To achieve this, we have applied Valance-Instrumentality-Expectancy (VIE) theory (Vroom, 1964) to identify these motivational factors instrumental to implement social media for knowledge sharing (Snead and Harrell, 1994; Hertel et al., 2003). With this help, we have proposed a conceptual model and derived some hypotheses. The proposed model has been validated through PLS-SEM analysis (Shmueli et al., 2019; Hair et al., 2018) considering two moderators, KCs and KSs.

The remaining sections of this paper are structured as follows - the next section (i.e. Section 2) presents the prior literature on the use of social media on the exchange of knowledge. Further, Section 3 presents theoretical background and hypotheses development. Section 4 discusses the methodology used in the paper. Section 5 presents data analysis and results of the data gathered from respondents. The subsequent section (i.e. Section 6) discusses results of the 
research with theoretical contributions, implications to practice and limitations and future research directions. The last section (i.e. Section 7) concludes the research.

\section{Literature Review}

Earlier studies have highlighted that the use of social media has positive impact on exchange of knowledge (Kim and Lee, 2006; Carlson et al., 2019). Several factors can be considered to influence the motivation of the stakeholders of higher education institutions towards knowledge sharing. It is essential to synthesize the psychology behind the stakeholders' motivation towards using social media for knowledge sharing (Nielsen and Razmerita, 2014). The individuals' motivation depends on several factors depending on the contextualities, which include, among others, cost benefit, trust, and technical skill (Casimir et al., 2012; Razmerita et al., 2014). The stakeholders of higher education institutions are also motivated for sharing of their knowledge by using social media as it provides pleasure to the knowledge sharers that they can help others easily and quickly in a cost effective manner to solve any problem (Hsu et al., 2007; Paroutis and Saleh, 2009). No doubt that interactions among faculties, students and between students and faculties of higher education institutions are always considered effective for the sharing of knowledge (Bock et al., 2005; Rahmi and Indarti, 2019). This process of interaction becomes easy, less costly if it is undertaken using social media (Yates and Paquette, 2011; Osatuyi, 2013; Ma and Chan, 2014; Weiger et al., 2019). It is also a fact that there should be motivation of the KCs to transfer knowledge to others and the KSs must be motivated to digest the transferred knowledge. These two acts as effective moderators (Chang and Chuang, 2012). Sharing of knowledge in higher educational institutions among the stakeholders enhances the standard of the institutions (Howell and Annansingh, 2013; Linzalone et al., 2020). If the faculties or the students or even the academic staff of institutions of higher education feel that knowledge exchange would help their own job, they can take help 
of any process for knowledge sharing. However, such sharing of knowledge will be effective and more enriched if processed through social media platform since it provides option of others to provide valuable inputs (Tan and Noor, 2013). In that case, their intention to use social media for knowledge sharing would be stronger (Jolaee et al., 2014; Iqbal et al., 2011; Read et al., 2019). Studies revealed that perceived usefulness has a direct effect on the use of modern technology (Yu et al., 2010; Mc Gowan et al., 2012; Ramayah et al., 2013; Tan and Noor, 2013; Yi, 2019).

Perceived usefulness is an important factor to motivate the stakeholders (students, faculties, and other administrative staffs of educational institutions) for the use of social media for knowledge sharing in higher learning institutions (Chang and Yang, 2013; Goswami and Agrawal, 2019). With increase in the social media usage for knowledge sharing, the stakeholders of higher education institutions would feel the importance of using the social media platform. The stakeholders' (students, faculties, and other administrative staffs of educational institutions) intention for knowledge sharing through other means, other than through social media platform, would not help them more to gain effective inputs from many other knowledgeable persons who might have previous experience in that issue of discussion (Sugathan et al., 2018; Seitz and Misra, 2020). Hence, the exchange of knowledge through social media appears to have additional advantage over and above other processes of sharing of knowledge, if the social media is trustworthy (Reagans and McEvily, 2003; Charband and Jafari, 2018). In that case, they would intend to use social media for exchange of knowledge. They must have some experience to use social media. It would help for knowledge sharing to facilitate their motivation (Stantchev et al., 2014; O’Leary et al., 2019).

The knowledge of theoretical studies and the review of studies of literature transpire that if the stakeholder of higher education institutions in India can feel the importance of sharing of knowledge, the usefulness of social media as means of sharing knowledge, and if they can 
acquire proper experience in this context (Kim and Ju, 2008; Chang and Yang, 2013; Goswami and Agrawal, 2019), they would be motivated to use social media for the use of knowledge exchange.

\section{Theoretical Background and Hypotheses Development}

It has been observed that VIE theory proposed by Vroom (1964) has found its successful application to accurately identify the motivational factors like rewards, self-confidence, experience and perceived difficulties (Chiang et al., 2008), which contribute an individual for being motivated towards successful adoption of any type of modern technology (Snead and Harrell, 1994; Li, 2011). This theory highlights that individuals would exhibit a behavioural intention in terms of valance, instrumentality, and expectancy. If the individual is perceived to have a potential outcome (i.e. valance); if he/she felt that by performing such behaviour, they would achieve a particular and targeted outcome (i.e. instrumentality); and if he/she perceived that by performing such behaviour, they can expect a particular performance (i.e. expectancy), then he/she will intend to behave accordingly. Practically, the motivation is considered as an outcome of the individual's expectation. It indicates that a specific effort will lead to the intended targeted performance. The instrumentality is considered to achieve a certain result by such performance. The desirability and optimism of this result concerning individual is considered as valance (Condrey, 2005). Expectancy is associated with effort (E) to performance $(\mathrm{P})$, i.e. $\mathrm{E} \rightarrow \mathrm{P}$, instrumentality is related with performance $(\mathrm{P})$ to outcome $(\mathrm{O})$, i.e. $\mathrm{P} \rightarrow \mathrm{O}$ and valance is conceptualised as outcome $(\mathrm{O})$ to reward $(\mathrm{R})$, i.e. $\mathrm{O} \rightarrow \mathrm{R}$ (Lawler et al., 1973). In the context of the present study, it is perceived that the VIE theory (Vroom, 1964) is deemed relevant because it nurtures individual's motivational behaviour for social media use for knowledge sharing in academia. If the user feels that knowledge sharing is important for their better job performance, they would intend to behave accordingly. Again, if an individual perceives that using social media (this is performance) may lead to improved knowledge 
sharing activities (this is outcome), they will intend to behave accordingly. Meaningful efforts are to be given to improve the social media usage in learning activities. Use of social media can improve the performance in knowledge sharing through Efforts $(\mathrm{E}) \rightarrow$ Performance $(\mathrm{P})$. If the individual possesses some experience in using social media, that will help to improve their learning capability to use it for knowledge sharing purpose in educational activities. In that way, the VIE theory would help extract two predictors i.e. importance and experience for intending to perform the targeted behaviour (i.e. use of social media for knowledge sharing). Again, we have used TAM (Davis et al., 1989) as TAM is considered as robust parsimonious model to predict users' acceptance of a new technology. Perceived usefulness, one of the core constructs of TAM, is considered as a strong determinant towards intention to use a new technology and the other construct of TAM, perceived ease of use can exhibit less consistent impact on intention (Venkatesh and David, 2000). In such context, it is essential to consider perceived usefulness as one of the predictors of intention in this study. Various studies have revealed that use of VIE theory and TAM could interpret use of social media for knowledge exchange in institutions of higher education (Ambrose and Kulik, 1999).

\subsection{Importance of Knowledge Exchange (IKE)}

The stakeholders would exhibit their interest of use of social media for the exchange of knowledge if they can feel that such exchange of knowledge is important for development of their respective jobs (Kim and Ju, 2008; Beckhard and Harris, 1987). It is important to note that if the stakeholders of higher education institutions feel that the existing store of knowledge is adequate for their jobs, there is no deficiency, they would not want to seek more knowledge. They would not feel importance of knowledge sharing. On the contrary, if the non-teaching staff, students and faculties feel that there are deficits in knowledge exchange, their readiness to reorient their behavioural intention to acquire more knowledge to fill up the deficits would grow (Kim and Ju, 2008). They will try to seek the knowledge if they get appropriate sources 
for contributing such knowledge to them. They would then use the modern technology, that is, social network for exchange of knowledge feeling its importance (Iqbal et al., 2011; Bughin and Chui, 2013; Fullwood et al., 2013). Hence, perception of stakeholders of institutions of higher education regarding importance of knowledge exchange would motivate them to use social media for sharing of knowledge. Judged from this important standpoint, the following hypothesis is formulated.

H1: In case, the stakeholders feel there is deficit of knowledge exchange, they would feel Importance of Knowledge Exchange (IKE) through knowledge management system which would significantly \& positively impact on their Intention to Use Social Media (IUS) for knowledge exchange.

\subsection{Perceived Usefulness of Social Media (PUS)}

Whenever a modern technology is implemented, it is considered important to emphasize on its usefulness, that is, when an individual would use a modern technology, he/she must have belief and confidence that such use would fetch the purpose for which it has been designed (Hertel et al., 2003). If the users feel that use of social media tool would be instrumental to effectively improve sharing of knowledge activities, the users will be motivated to intend to use it to acquire knowledge from knowledge contributors perceiving its usefulness. In other words, we can say perceived usefulness of social media would impact on the users to intend to use social media for knowledge exchange. The effect of such knowledge exchange would be fruitful through social media if that takes place between knowledge seekers and knowledge contributors in an conducive atmosphere by the help of knowledge management system (Chen et al., 2010). In the context of use of social media, there are number of studies which supported this prediction (Moeser et al., 2013; Chang and Yang, 2013). In terms of observation of Venkatesh and Davis, 2000, the perceived usefulness always triggers intention behaviour and perceived usefulness is the outcome of the concepts of several interrelated social and cognitive 
instrumental forces as mentioned above. In terms of the above discussions, the following hypothesis is developed.

H2: Perceived Usefulness of Social Media (PUS) has a significant and positive impact on the intention to Use Social Media for Knowledge Exchange (IUS) provided the knowledge seekers and knowledge contributors can create a conducive atmosphere for such knowledge exchange.

\subsection{Experience using Social Media (EUS)}

It is a common experience that if the users feel confident in exchange of knowledge in a congenial environment between the knowledge seekers and knowledge contributors, they will be more motivated to share knowledge (Kankanhalli et al., 2005; Yoo et al., 2012). In the early stage when the users start to use a modern technology, it is difficult to have expectancy. In this initial stage of use, if the users possess some experience of usage, it will act as an important indicator of expectancy (Vroom, 1964). When the tools are used by the users for non-work purposes, skill would develop and there will be development of insights about the fact as to what these tools can achieve (Archambault and Grudin, 2012; Tan and Noor, 2013). Frequent and continuous use of social media for purposes even not connected with knowledge sharing, would be helpful to gain experience. This experience (Linzalone et al., 2020) of use of social media would impact the use of this tool for sharing of knowledge. From these vital discussions, we can derive the following hypothesis:

H3: More Experience in Using Social Media (EUS) would significantly and positively impact on the Intention to Use Social Media (IUS) for knowledge exchange.

With all these considerations including consideration of two moderators ( $\mathrm{KC}$ and $\mathrm{KS}$ ), the conceptual model is provided. It is shown in Figure 1. 


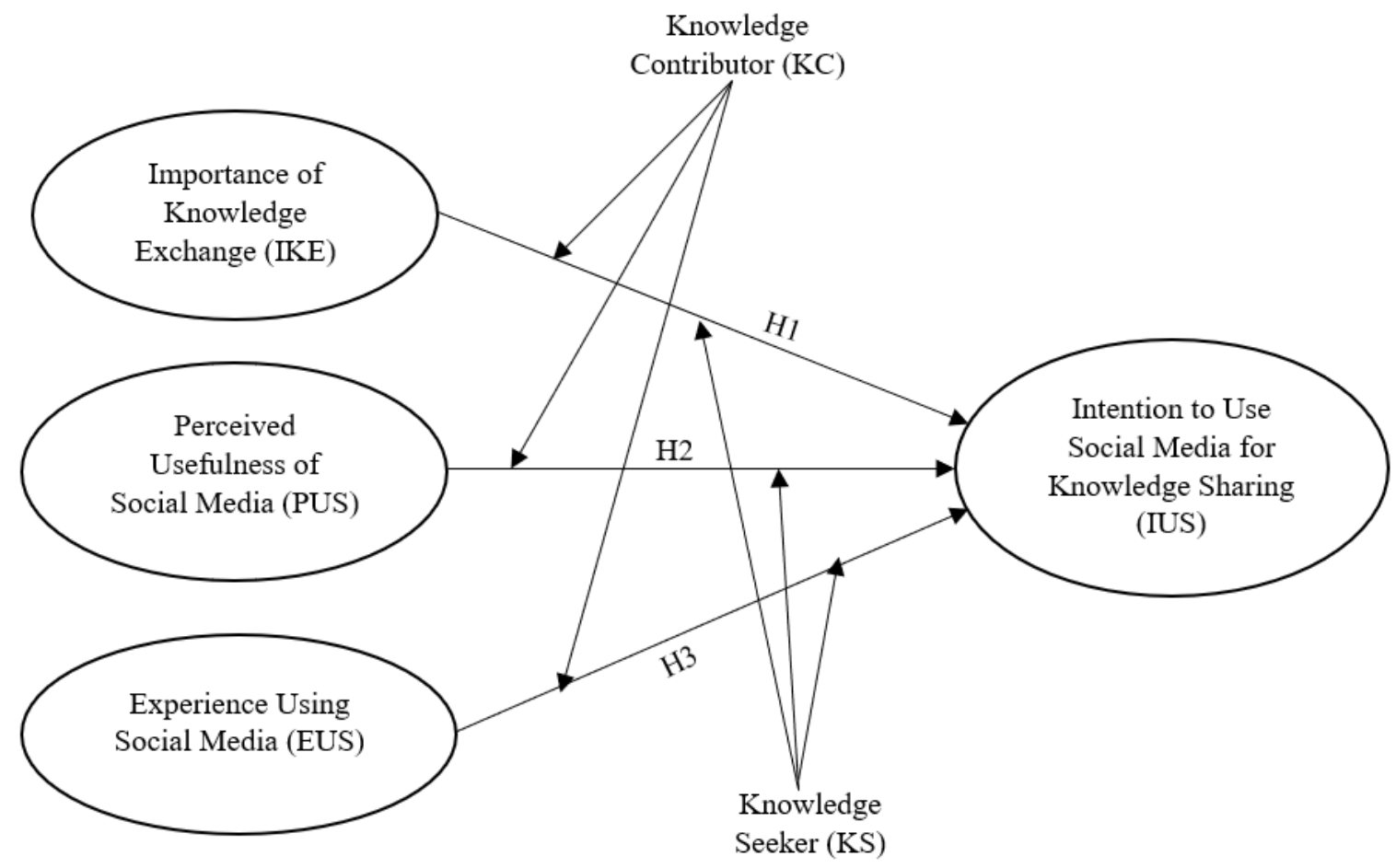

Figure 1. Conceptual Model

\subsection{Consideration of Moderators}

Sustenance of knowledge management is necessary in the institutions of higher education in India. It needs active participation of the users (participates). Some of the stakeholders would contribute knowledge to the KSs. Lack of activities from either side would pose effective impediment in the process of exchange of knowledge (Davenport \& Prusak, 1998; Goswami and Agrawal, 2019). If the individuals need more information for their satisfaction, they are considered as knowledge seekers (KSs). Their appetite to gain knowledge would be removed by the knowledge contributors (KCs). KCs are those who are willing to part with their knowledge and intend to share that knowledge through Knowledge Management System (KMS) to others (Chen et al., 2010). KSs are those who usually enter into the system for searching the knowledge they would need by using key words. After getting the information, the KSs examine the results. Sometimes the KSs also click the results so obtained for going deeper into the results. Even, sometimes, the KSs are found to have forwarded the information 
to other people who might be interested in that information (Sutanto and Jiang, 2013). On the contrary, working for storing of important knowledge will be valueless if any one does not want to have it. Hence, it is needed to bring a balance between these two moderators, KCs and KSs. These two factors, as such, act as good moderators to impact on 'Intention to Use Social Media for Knowledge Sharing' (IUS) by 'Importance of Knowledge Exchange' (IKE), that is, IKE $\rightarrow$ IUS, on 'Intention to Use Social Media for Knowledge Sharing' (IUS) by 'Perceived Usefulness of Social Media' (PUS), that is, PUS $\rightarrow$ IUS and on 'Intention to Use Social Media for Knowledge Sharing' (IUS) by Experiencing Using Social Media' (EUS), that is, EUS $\rightarrow$ IUS. In this study, we have considered these two moderators to investigate how they influence the results.

\section{Research Methodology}

We have already provided a conceptual model as shown in Figure 1. Now, the validity of this conceptual model is required to be tested through statistical tools. The conceptual model shows that there are three independent variables like IKE, PUS and EUS impacting on the dependant variable IUS. The conceptual model has been validated using PLS-SEM analysis. This process has been used because it does not impose any sample restriction. This study has dealt with 320 valid samples. Besides, this study is concerned with organizational and human resource management issues. PLS-SEM analysis also becomes effective for such types of issue (Sosik et al., 2009; Hair et al., 2018; Ringle et al., 2019). For analysis using PLS-SEM approach, we use both PLS-Graph (Chin, 2003) and SmartPLS (Ringle et al., 2015). To apply PLS regression analysis for validation of conceptual model as well as for hypotheses testing, survey works are needed to be conducted by the way of having feedbacks from useable respondents against appropriate questionnaire. With the help of the literature review and with the help of conception lent from the four constructs, we have been able to prepare 22 questions (items). While preparing the items, due attention was given on their layout. It was assured that no 
controversial, leading, and ambiguous questions were set. The 22 questions were given to 7 experts to examine about their feasibility and readability. The experts were all from academic area each having PhD degree in the allied subject, that is, effect of social media on knowledge sharing in the field of higher education. Each of them has more than 8 years research experience in this field. They opined that out of 22 questions, eight suffer from the defect of readability. We did not consider those questions. We, as such, began with 14 items. Now, to target effective responses, we had to attend many conferences and seminars throughout last six months of 2017 in India in different places. The conferences and the seminars were concerned with discussions on application of social media for sharing of knowledge in higher education in India.

From those conferences and seminars, it was possible for us to select some institutions of higher education in India like Indian Institute of Technologies (IITs), Indian Institute of Managements (IIMs), Indian Institute of Information Technologies (IIITs) and National Law Universities (NLUs). We selected some of them randomly. After that, we contacted those institutions and picked up details of 109 faculties and 256 students, total being 365 . We sent to their emails these 14 questions with a request to send responses within 30 days from the date of receipt of communication. The questions were in the form of statements. Responses needed to be given through tick mark from strongly disagree to strongly agree in 5 divisions. Within stipulated time, we received 89 responses from the faculties and 240 responses from the students. 329 responses were obtained in total. These have been scrutinized by the seven experts. Out of 329 replies, nine responses were removed as those were incomplete. Studies have been started with 320 usable replies against 14 questions. The demographic information of 320 responses is shown in Table 1. The fourteen questions are shown in the appendix.

\section{Results}

The demographic information (see Table 1) shows that responses of $25.6 \%$ from faculties (82 out of 320 ) and $74.4 \%$ from students (238 out of 320) were taken. 
Table 1: Demographic information of the respondents $(\mathrm{N}=320)$

\begin{tabular}{ccc}
\hline Category & Number & Percentage (\%) \\
\hline Faculty & & \\
IITs & 32 & $10.0 \%$ \\
IIMs & 25 & $7.8 \%$ \\
IIITs & 15 & $4.7 \%$ \\
NLUs & 10 & $3.1 \%$ \\
Students & & \\
IITs & 106 & $33.1 \%$ \\
IIMs & 72 & $22.5 \%$ \\
IIITs & 38 & $11.9 \%$ \\
NLUs & 22 & $6.90 \%$ \\
\hline
\end{tabular}

\subsection{Computation of LF, AVE and CR}

For identifying if the items can fully explain their own construct, Loading Factor (LF) of each item was to be computed. For detection of validity of constructs, Average Variance Extracted (AVE) has been measured for each construct. To identify if the constructs are reliable, Composite Reliability (CR) of each construct was estimated (Fornell and Larcker, 1981). The acceptable lowest value of LF is 0.707, AVE is 0.5 and CR is 0.7 (Barroso et al., 2010; Hair et al., 2011; Urbach et al., 2010). The results are shown in Table 2. It appears that all the parameters have values within acceptable range confirming reliability of items, validity, and reliability of constructs.

Table 2: Item loadings with AVE and CR

\begin{tabular}{|c|c|c|c|c|}
\hline Latent Variable (Construct) & Item & Loading & AVE & $\mathbf{C R}$ \\
\hline \multirow[t]{5}{*}{ Importance of Knowledge Exchange (IKE) } & & & 0.82 & 0.89 \\
\hline & IKE1 & 0.92 & & \\
\hline & IKE2 & 0.90 & & \\
\hline & IKE3 & 0.89 & & \\
\hline & IKE4 & 0.91 & & \\
\hline \multirow[t]{4}{*}{ Perceived Usefulness of Social Media (PUS) } & & & 0.84 & 0.91 \\
\hline & PUS1 & 0.87 & & \\
\hline & PUS2 & 0.96 & & \\
\hline & PUS3 & 0.92 & & \\
\hline \multirow[t]{5}{*}{ Experience Using Social Media (EUS) } & & & 0.83 & 0.89 \\
\hline & EUS1 & 0.94 & & \\
\hline & EUS2 & 0.88 & & \\
\hline & EUS3 & 0.89 & & \\
\hline & EUS4 & 0.93 & & \\
\hline \multirow{4}{*}{$\begin{array}{l}\text { Intention to Use Social media for Knowledge } \\
\text { Sharing (IUS) }\end{array}$} & & & 0.88 & 0.93 \\
\hline & IUS1 & 0.94 & & \\
\hline & IUS2 & 0.96 & & \\
\hline & IUS3 & 0.92 & & \\
\hline
\end{tabular}




\subsection{Measurement Model}

For reliability of constructs, we have also estimated Cronbach's alpha of each construct. Its lowest acceptable value is 0.6 (Hair et al., 1998). To establish discriminant validity, which confirms that each item can explain fully its own construct and can weakly explain other constructs, we have computed average variance of each construct. If the average variance (AV) of each construct is greater than Pearson's correlation coefficients of each construct with other constructs, we say discriminant validity has been established. It is to note that, AV is square root of AVE. The entire results along with computation of Mean and Standard Division (SD) are shown in Table 3. In Table 3, the square roots of AVEs are shown in diagonal positions whereas the Pearson's correlation coefficients are shown in off-diagonal positions. It appears that values of Cronbach's alpha $(\alpha)$ are all greater than 0.6 and the square roots of AVEs are also greater than the correlation coefficients. Results confirm reliability of constructs and it also establishes discriminant validity (see Table 3). For discriminant validity, we have also considered effect of the two moderators (KC and $\mathrm{KS}$ ).

Table 3: Measurement Model Estimation

\begin{tabular}{ccccccccccc}
\hline Construct & ICR( $(\boldsymbol{\alpha})$ & Mean & SD & AVE & IKE & PUS & EUS & IUS & KC & KS \\
\hline IKE & 0.82 & 4.41 & 1.42 & 0.82 & $\mathbf{0 . 9 1}$ & & & & & \\
PUS & 0.91 & 5.21 & 1.35 & 0.84 & 0.47 & $\mathbf{0 . 9 2}$ & & & \\
EUS & 0.87 & 4.08 & 1.61 & 0.83 & 0.49 & 0.43 & $\mathbf{0 . 9 1}$ & & \\
IUS & 0.94 & 3.21 & 1.42 & 0.88 & 0.36 & 0.46 & 0.39 & $\mathbf{0 . 9 4}$ & & \\
KC & 1.00 & 0.69 & 0.49 & 1.00 & 0.17 & 0.31 & 0.32 & 0.41 & $\mathbf{1 . 0 0}$ & \\
KS & 1.00 & 0.82 & 0.32 & 1.00 & 0.21 & 0.26 & 0.20 & 0.19 & 0.24 & $\mathbf{1 . 0 0}$ \\
\hline
\end{tabular}

\subsection{Structural Model}

The structural model has been estimated using bias-correlated as well as accelerated bootstrapping approach with consideration of 5,000 samples. The blindfolding approach is used with omission interval of five for obtaining cross-validated measures of redundancy for the endogenous variable (Mishra et al., 2017). Through this procedural approach, the value of $\mathrm{Q}^{2}$ obtained was 0.62 . This obviously indicates that the model possesses large predictive relevance of PLS-path model (Hair et al., 2018). For assessing the overall model fit, recommendations of 
Henseler et al. (2014) have been followed. For validation of the model, SRMR (Standardized Root Mean Square Residual) has been utilised and estimated as an index. The assessment of model estimation through PLS transpired the value of SRMR as 0.065 and the assessment of PLS reveals SRMR value of 0.036. Generally, the acceptable highest value in this context is considered as 0.08 (Hu and Bentler, 1999). Hence, the model is said to be in order.

\subsection{Path Coefficients and p-values}

The path coefficients and p-values (level of significance) of the hypotheses along with coefficient of determination $\left(\mathrm{R}^{2}\right)$ have been estimated and shown in Table 4. This signifies to what extent hypotheses are supported, how the moderators could provide impact on the result and what is the explanative power of the model.

Table 4: Path Coefficient and p-values

\begin{tabular}{lcc}
\hline Particulars & Path Coefficient/Variance & p-value \\
\hline $\mathrm{IKE} \rightarrow \mathrm{IUS}$ & 0.36 & $<0.01\left({ }^{* *}\right)$ \\
$\mathrm{PUS} \rightarrow \mathrm{IUS}$ & 0.42 & $<0.01(* *)$ \\
$\mathrm{EUS} \rightarrow \mathrm{IUS}$ & 0.47 & $<0.01\left({ }^{* *}\right)$ \\
$(\mathrm{IKE} \rightarrow \mathrm{IUS}) \times \mathrm{KC}$ & 0.62 & $<0.01\left({ }^{* *}\right)$ \\
$(\mathrm{IKE} \rightarrow \mathrm{IUS}) \times \mathrm{KS}$ & 0.59 & $<0.01(* *)$ \\
$(\mathrm{PUS} \rightarrow \mathrm{IUS}) \times \mathrm{KC}$ & 0.64 & $<0.01(* *)$ \\
$(\mathrm{PUS} \rightarrow \mathrm{IUS}) \times \mathrm{KS}$ & 0.63 & $<0.01(* *)$ \\
$(\mathrm{EUS} \rightarrow \mathrm{IUS}) \times \mathrm{KC}$ & 0.18 & $<0.01(* *)$ \\
$(\mathrm{EUS} \rightarrow \mathrm{IUS}) \times \mathrm{KS}$ & 0.06 & $>0.05\left({ }^{\mathrm{n}}\right)$ \\
$\mathrm{R}($ on $\mathrm{IUS})$ & 0.87 & \\
\hline
\end{tabular}

In Table 4, the value of path coefficient of IKE $\rightarrow$ IUS is 0.36 . It interprets that ignoring the effect of residual influence as well as effects of other independent variables, it can be inferred that IUS $=0.36$ (IKE). Similarly, by ignoring the residual influence and effects of other independent variables, the value of path coefficient of PUS $\rightarrow$ IUS is 0.42 i.e. IUS $=0.42$ (PUS). Similarly, the effect of other independent variables on IUS can be interpreted. The results of path coefficient show that effect of moderator KS on the path EUS $\rightarrow$ IUS is low (i.e. 0.06). It implies that effect of EUS on IUS is negligibly influenced by the moderator KS. The overall results show that path coefficients of $(\mathrm{IKE} \rightarrow \mathrm{IUS}) \times \mathrm{KC}$ and of $(\mathrm{IKE} \rightarrow \mathrm{IUS}) \times \mathrm{KS}$ are 0.62 and 0.59 respectively with significant levels $\mathrm{p}<0.01(* *)$ for both (see Table 4$)$. It also signifies 
that two moderators have effective influence on H1 (IKE $\rightarrow$ IUS). We have hypothesized that perceived usefulness of social media (PUS) has a significant and positive impact on the intention to use of social media for knowledge exchange (IUS). In this context, empirical analysis reveals that perceived usefulness is found to have related to stronger intention of knowledge seeking $(\beta=0.63, p<.01(* *))$. It is also related to stronger knowledge contribution intention $(\beta=0.64, \mathrm{p}<.01(* *))$. Thus, the empirical analysis confirmed that Perceived Usefulness of Social Media (PUS) has a significant and positive impact on the intention to Use Social Media for Knowledge Exchange (IUS) provided the knowledge seekers and knowledge contributors can create a conducive atmosphere for such knowledge exchange. It confirms $\mathrm{H} 2$. The results are shown using the validated model in Figure 2.

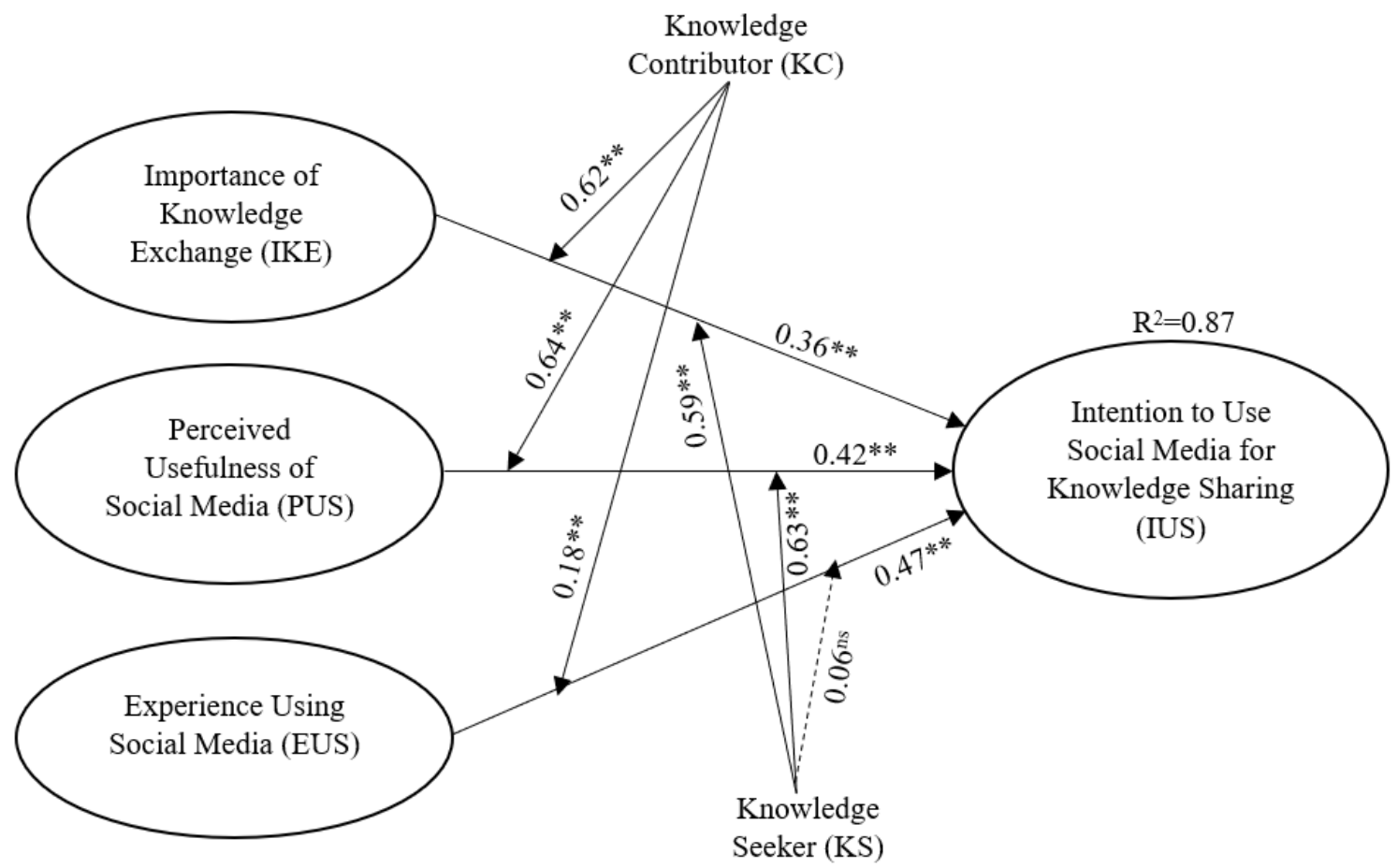

Figure 2: Validated Model

\section{Discussion}

This study uses VIE theory to determine the knowledge exchange behaviour of academics. The effect of variables such as knowledge contributor and knowledge seeker has been used as 
moderators for the proposed model. The hypotheses for all direct and moderated relationships between variables for the given proposed research model were found significant. To begin with, the testing for hypothesis $\mathrm{H} 1$ (IKE $\rightarrow$ IUS) is supported. This relationship has also received support from some prior studies (Iqbal et al., 2011; Bughin and Chin, 2013). For example, in the study conducted by Iqbal et al. (2011) in the University Technology Malaysia (UTM), it was highlighted that knowledge exchange has effective impact on innovation capacity. Moreover, the survey report published through the study of Bughin and Chin (2013) highlights that adoption of social media tools for knowledge sharing in different functionalities of companies could spur additional benefits. It is also supplemented by VIE theory. The model also shows support for PUS $\rightarrow$ IUS (H2). It is supplemented by Venkatesh and Davis (2000) wherein that study has explained that perceived usefulness acts as a strong driver of intention. Perceived usefulness also includes impacts of several social forces as well as cognitive instrumental process factors. EUS $\rightarrow$ IUS (H3) indicates the support of the further hypothesis. This result is aligned with the VIE theory (Vroom, 1964) and it has been supplemented by earlier studies (Chen et al., 2010). In this study by Chen et al. (2010), investigations were made in two IT oriented Professional Virtual Communities (PVCs) in Taiwan. This study transpired that PVCs could bring geographically dispersed communities closer for knowledge exchange to derive effective benefits provided the involved communities should know how to use knowledge sharing tools. The effects of the moderators $\mathrm{KC}$ and $\mathrm{KS}$ on the three linkages $\mathrm{H} 1$, $\mathrm{H} 2$ and $\mathrm{H} 3$ have been validated through PLS-SEM analysis, which have also received support from earlier studies (e.g. Susanto and Jiang, 2013). Susanto and Jiang (2013), with the help of appraisal theory, investigated the effects of knowledge contributors and knowledge seekers in MNCs. This study also concluded that knowledge contributors and knowledge seekers have effective contributions in knowledge management system in MNCs. However, in our study, the moderating effects of KS on the linkage EUS $\rightarrow$ IUS (H3) have not been supported as the 
concerned path coefficient is too low (0.06) with non-significance $(\mathrm{p}>0.05)$ of the relationship. This has contradicted by earlier studies (e.g. Tan and Noor, 2013). Tan and Noor (2013), in the context of Malaysian University, observed that knowledge seekers effectively influence the impact of experience on intention of using social media for knowledge sharing. But this has not been supported in our study presumably because acquisition of knowledge by KS is more difficult compared to seeking knowledge.

To analyse how $\mathrm{KS}$ and $\mathrm{KC}$ have impact over the participants perceiving high deficits of knowledge exchange and perceiving low deficits of knowledge exchange, simple slope analysis has been conducted (Aiken and West, 1991). In Figure 2, the result has been highlighted graphically. It reveals that there exists a positive relation between importance of knowledge exchange with knowledge seeking intention. This is applicable for those participants who perceive high deficits in exchange of knowledge. This concept has supported Hypothesis 1. However, this relationship does not occur for those participants who perceive low deficit in knowledge sharing. It is inferred that in consonance with Hypothesis 1, it appears that Importance of Knowledge Exchange (IKE) impacts Intention of Knowledge Contribution. However, this is only applicable for those participants who perceive high deficits in exchange of knowledge. This relation does not exist relating to those participants who perceive low deficit in knowledge sharing. Here, to interpret the situations (Figure 2), one Knowledge Seeker (KS) against Knowledge Sharing and another Knowledge Contributor (KC) against Knowledge Sharing (in both the graphs) in the matter of interactions with reference to high and low shortfall of knowledge sharing, the regression lines have been plotted in terms of the recommendation of Aiken and West (1991). Again, it is known that "any distribution of data is likely to contain some extreme scores" (Keppel and Wickens, 2014; p.146). Commonly, for tracing the regression line, values are estimated for the $\mathrm{X}$-axis at the mean, one SD above the mean and one SD below the mean (Cohen and Cohen, 1983) and then regression lines are platted. In this 
figure, the lines have been drawn within -1SD and +1SD covering the mean. Further, Figure 3 shows separately the reactions of $\mathrm{KS}$ and reactions of $\mathrm{KC}$ in relation to knowledge sharing. Knowledge Seekers-Knowledge Sharing two straight line graphs imply separately that if the KSs have high short fall of knowledge, that is, if the KSs possess less knowledge, the red line with positive slope indicates that with increase of knowledge sharing, the importance of KS having high deficit of knowledge considerably increases. It implies that KS possessing less knowledge puts more importance in sharing of knowledge.

Further, Knowledge Seeker - Knowledge Sharing, blue coloured straight line graph with negative slope indicates if the KSs possess less shortfall of knowledge (possess comparatively high knowledge), with increase of knowledge sharing, the KSs having less shortfall of knowledge exhibit less importance to gain knowledge. In a word, this blue line having negative slope indicates that if the KSs have less short fall of knowledge, they attach less importance towards knowledge sharing. Again, Knowledge Contributor - Knowledge Sharing two straight line graphs (one in red colour and other in blue colour) imply separately that if the KCs (Red coloured straight line graph with positive slope) find that the KSs possess high shortfall of knowledge, that is, if the KSs have less knowledge, the KCs put much importance to share knowledge as is shown through red coloured straight line graph. On the contrary, if the KCs feel that KSs possess some knowledge, that is, if the KSs have less shortfall of knowledge, the KCs put less importance to share knowledge to them, that is, in that case with increase of knowledge sharing, the importance of $\mathrm{KC}$ decreases as shown through blue straight line with negative slope. 

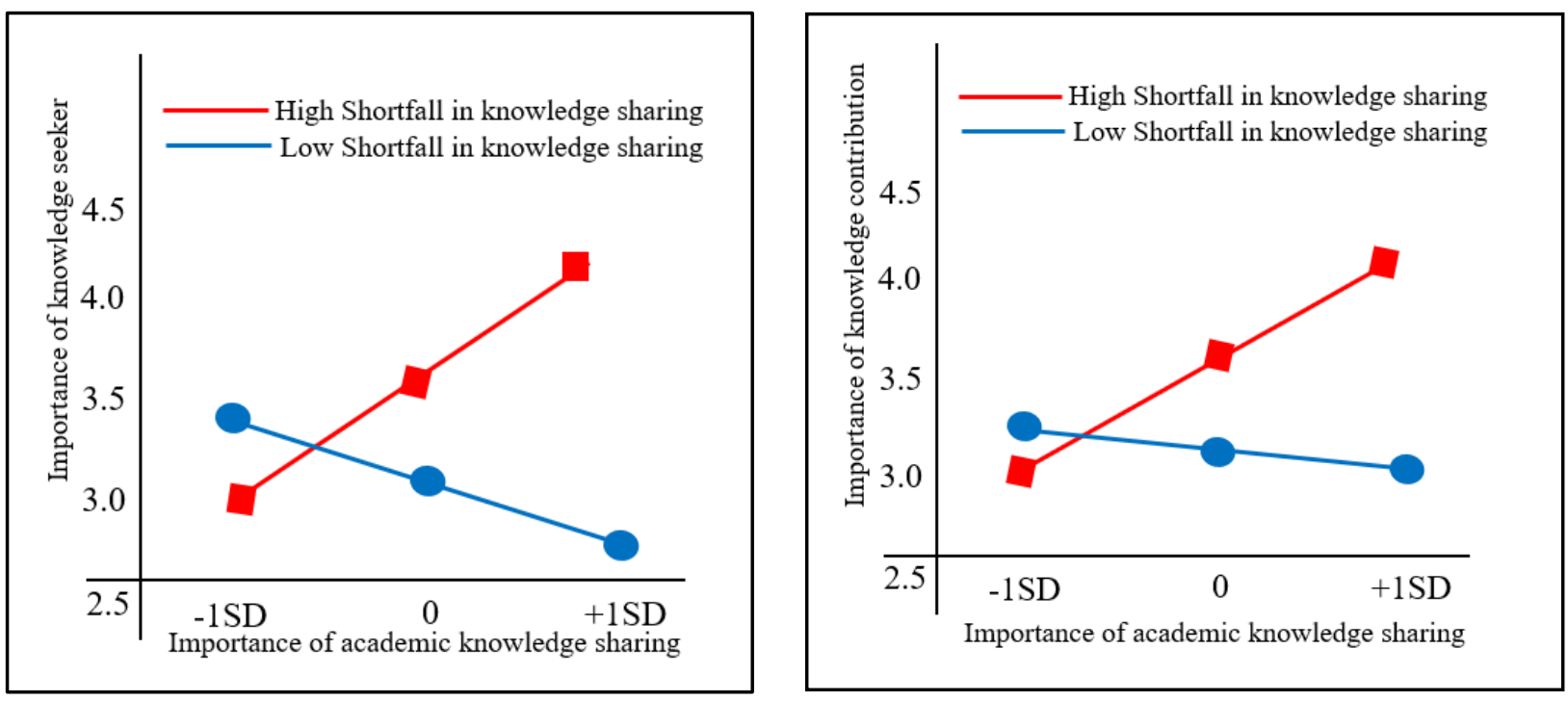

Figure 3: Moderators' effect

It is to note that the low shortfall in knowledge sharing line is referred by circles whereas the high shortfall in knowledge sharing is referred by squares. We have also hypothesized (H3) that Experiences in Using Social Media (EUS) would significantly and positively impact on the intention to use social media for Knowledge Exchange. From the study of empirical analysis, it appears that though there exists a significant relationship between experience of social media and knowledge contribution $(\beta=0.18, \mathrm{p}<.01(* *))$, the relationship between experience of social media and knowledge seeking appears to be marginal $\left(\beta=.06, p<.05\left(^{*}\right)\right.$ as has already been mentioned. Hence, we can infer that $\mathrm{H} 3$ is partly supported due to weak influence of KS on EUS $\rightarrow$ IUS. Results transpire that $\mathrm{H} 1$ and $\mathrm{H} 2$ are supported but $\mathrm{H} 3$ is partly supported.

\subsection{Theoretical Contributions}

Our study has provided several theoretical contributions in the extant literature. In this context, it is observed that the survey (Bughin and Chin, 2013) in different companies transpired that knowledge sharing derives much benefits to the companies, especially, when such sharing takes place with the help of social media platform as it could spur additional benefits. From the study of two professional virtual communities (PVCs) namely programmer-club community and blue shop community of Taiwan, Chin et al. (2010) observed that PVCs can form effective 
communities for knowledge sharing through social media platforms. Again, the study by Susanto and Jiang (2013) highlighted that, in the context of MNCs, role of KCs and KSs is vital. But, in our study we have shown that experience of using social media, perceived usefulness of using social media and understanding the importance of knowledge exchange together impact the intention to use social media for knowledge sharing in academia. Before this study, none of the other studies showed that these three factors together act as predictors for intention to use social media in academics.

Moreover, this study has considered the effects of knowledge contributors and knowledge seekers as two moderators, which have contributed in-depth understanding between the relationships of variables on intention to use social media for knowledge sharing. Moreover, none of the extant literature transpires the explicit contribution of knowledge sharing by the help of social media platforms in academia, especially, in the Indian context. This is claimed to be a specific theoretical contribution of this study.

Our study has provided a model where importance of knowledge exchange (IKE), perceived usefulness of social media (PUS), and experience using social media (EUS) simultaneously impact intention to use social media for knowledge sharing (IUS). No existing studies have used these three exogeneous variables in the context of knowledge sharing through social media platforms in higher educational institutions. The model which has been proposed in this study is a unique model and has not been proposed earlier. This is one of the unique theoretical contributions of our study.

Our study has considered the impacts of the moderating effects of knowledge contributors (KCs) and knowledge sharers (KSs) in the proposed theoretical model. Consideration of the effects of KCs and KSs as moderators has made our model unique. This study has considered the moderating effects of KCs and KSs on the linkages between intention to use social media for knowledge sharing and their different predictors. Consideration of these two moderators 
KCs and KSs has added value to our model. It has been able to manifest a clear realization in the context of knowledge sharing in the higher educational institutions by the use of social media platforms which was not found in any other model provided in other studies. This is claimed to be a special theoretical contribution to our study.

Our study has considered three exogeneous variables IKE, PUS, and EUS to impact IUS. All these three linkages were found significant as was observed after PLS-SEM analysis since the corresponding path coefficients are quite high in this context with high level of significance yielding better predictive power of the model. The details of the theoretical implications of the validated model are shown in Table 5 below.

Table 5: Theoretical Implications of the validated model

\begin{tabular}{|c|c|c|}
\hline Path & $\begin{array}{l}\beta \text { - value } \\
\text { (Significance level) }\end{array}$ & Theoretical Implication \\
\hline $\mathrm{IKE} \rightarrow \mathrm{IUS}$ & $+0.36 * *(\mathrm{p}<0.01)$ & $\begin{array}{l}\text { The impact of IKE significantly and positively impacts IUS. The } \\
\text { significance of this relationship (IKE } \rightarrow \text { IUS) was not explicitly } \\
\text { studied in other research in the context of knowledge sharing through } \\
\text { social media in higher educational institutes. This is one of the unique } \\
\text { contributions of this study. }\end{array}$ \\
\hline PUS $\rightarrow$ IUS & $+0.42 * *(\mathrm{p}<0.01)$ & $\begin{array}{l}\text { This relation implies that PUS significantly and positively impacts } \\
\text { IUS. There are other studies where perceived usefulness was } \\
\text { considered as an important predictor of acceptance and use of a new } \\
\text { technology like mobile learning (m-learning) (Yong et al., 2010; Park } \\
\text { et al., 2011; Park et al., 2012). However, no other studies analyzed } \\
\text { the impact of perceived usefulness in the context of knowledge } \\
\text { sharing using social media platforms in higher educational institutes } \\
\text { which has been done in our research study. In this respect, this study } \\
\text { is claimed to have provided unique theoretical contribution to the } \\
\text { extant literature. }\end{array}$ \\
\hline EUS $\rightarrow$ IUS & $+0.47 * *(\mathrm{p}<0.01)$ & $\begin{array}{l}\text { This result theoretically implies that IUS positively and significantly } \\
\text { impacts IUS by the stakeholders of higher educational institutes. No } \\
\text { other studies are known to have analyzed this relationship in the } \\
\text { context of knowledge exchange in higher educational institutes using } \\
\text { social media platforms which has been nurtured in our study. This is } \\
\text { also deemed to be considered as one of the important theoretical } \\
\text { contributions in our study. }\end{array}$ \\
\hline
\end{tabular}

The above table briefly shows that, the three exogeneous variables have explained the goal of this study (IUS). The consideration of these three exogeneous variables impacting intention to use social media for knowledge sharing in higher educational institutions is perceived to be significant in this context. This is because with consideration of these three variables (IKE, 
PUS, and EUS) along with consideration of the effects of the two moderators KCs and KSs, could achieve a high predictive power of $87 \%$ for the proposed research model.

\subsection{Implications to Practice}

To enrich the knowledge repository of the higher Indian institutions, it is important that all these stakeholders must be intimately involved in the process of exchange of knowledge (Latilla et al., 2018). In terms of the results of this study, the authorities must make the users aware regarding the utility of social media as an effective platform for knowledge sharing. In the context of higher educational institutions of India, it is pertinent to mention that the stakeholders of Indian higher institutions situated in semi urban areas need to be extensively and exhaustively trained since it will not be an exaggeration to comment that stakeholders of semi urban areas, barring a few, are construed to be less social media savvy so far as its usage is concerned. Hence, training is required to be administered in the individualized pattern. In terms of the validated hypothesis (IKE $\rightarrow$ IUS), it appears that if the stakeholders realize the importance of the knowledge sharing, they will intend to use social media for knowledge sharing purpose. Hence, the authorities of the higher education institutions must make effective policies so that the stakeholders are encouraged to use different social media platforms for knowledge sharing activities to achieve the highest potential from them. This could improve the academic standard of the higher education institutions.

If there is detection of deficits of knowledge sharing, the need of use of social media to enhance the sharing of knowledge becomes important. The authorities are to be serious at this issue. We have observed from our studies that the importance of perceived usefulness would improve knowledge sharing and therefore supporting Hypothesis H2 (i.e. PUS $\rightarrow$ IUS). But this was ultimately not strongly supported having lower path weightages. Hence, attention of the authorities to focus on this point is necessary. It is a common experience that easiness to use a system is an important predictor of perceiving the users regarding the usefulness of the system, 
especially, in the context of social media platform (Pinho and Soares, 2011). Hence, the stakeholders are to feel easy to use a system first and then the question of realization of usefulness of that system arises. Here in this study, perception of usefulness did not strongly impact on the intention to use the system. This leads to construe that the users are to be made savvy to use the system first. This provides much food for reflection to the authorities for rendering the stakeholders savvy to use social media.

Since results show that by gaining more experience in using social media, the stakeholders will be more intended in knowledge sharing (i.e. H3 (EUS $\rightarrow$ IUS)), the authorities are required to train the users appropriately so that they can gain more experience. The managers are also to be vigilant to watch that knowledge gained by the students, faculties and administrative staffs (stakeholders) of higher institutions of India not only gain knowledge through exchange of knowledge but they are capable of applying such knowledge in the practical field strategically.

\subsection{Limitations and Future Research Directions}

In India, knowledge sharing by the stakeholders of higher education institutions in India with the help of social media has not taken place to the full extent. In that scenario, we have conducted our survey works with the help of 320 usable responses. The concerned respondents have no direct experience relating to use of social media in knowledge sharing in their respective institutions as this system has not been fully adopted there. However, it is a fact that these respondents might have enough experience in using social media for other purposes. The respondents who have been considered during survey are from academic origin. Though their feedback is predictive in the present context, it may be safely presumed that their responses would be more proximal to the reality under the circumstances. Hence, proper caution needs to be taken while generalising the result for adopters. India is a vast country with diversified culture (Hofstede, 1997). This issue of concerned culture of individuals might influence their adoption intention (Giudice et al., 2012). 
We have conducted our survey using 320 usable responses. Assessing the vastness of the country, this figure should not be considered to provide a generic picture. Besides, we have conducted our survey for a limited period. To maintain generalisability, a longitudinal study with more usable responses is essential.

We have used here two moderators i.e. KC and KS. It is not known if use of any other relevant moderator(s) in addition could improve the model (Nistor, 2014; Sumak et al., 2011). We have considered in our survey, some institutions of higher education at the national level. We did not consider other institutions at provincial levels. This non-consideration might be construed as another limitation. It is left for the future researchers to nurture the above-mentioned untouched points.

\section{Conclusion}

To achieve success in any organization, knowledge management is considered as one of the important strategic challenges. Improvement of knowledge management strategy is intimately connected with knowledge sharing. In the perspective of knowledge sharing mechanisms, the role of social media is vital. This study has highlighted that social media acts as a helpful tool for knowledge sharing in higher educational organizations since such exchange of knowledge improves the performance of the organizations. Through different social media platforms, knowledge can be easily disseminated among the stakeholders of the higher education institutions. Knowledge management through knowledge sharing in higher education institutions is perceived to have successfully managed their knowledge repository by converting minimum inputs to maximum outputs. The study also revealed that this can be achieved by tactfully using internal resources with the help of available knowledge to create values. While augmenting the knowledge management strategy, the study transpired that the higher education institutions are facing entangled challenges consequent upon rapid change of pattern of knowledge-content involving the issues of modern knowledge economy. 
This study has successfully contributed to the insights as to how perception of individuals for the need of knowledge sharing provokes them to use social media as an effective tool. This study has emphasized on the necessity of knowledge management in the context of sharing of knowledge by the help of social media in the higher education institutions in India. Moreover, in consonance with concept of prior research, this study has been able to highlight the significance of perceived usefulness regarding sharing of knowledge with the help of social media platform. This study has also successfully analysed how experience can impact on the use of such technology (social media) for exchange of knowledge in the institutions of higher education in India. Use of two moderators is considered befitting since the model has exhibited high explanative power to the tune of $87 \%$. It is expected that the present analysis may help other developing and emerging countries to improve their knowledge sharing mechanism in their higher educational institutions and even in other type of organizations where updating knowledge of employees is needed.

\section{References}

Aiken, L. S. and West, S. G. (1991), Multiple regression: Testing and interpreting interactions, Newbury Park, CA: Sage.

Ambrose, M. L. and Kulik, C. T. (1999), "Old friends, new faces: Motivation research in the 1990s”, Journal of Management, Vol. 25 No. 3, pp. 231-292. http://dx.doi.org/ $10.1177 / 014920639902500302$.

Archambault, A. and Grudin, J. (2012), “A longitudinal study of Facebook, LinkedIn, \& twitter use. Proceedings CHI. pp. 2741-2750. http://dx.doi.org/10.1145/2207676.2208671.

Barroso, C., Carrion, G. C. and Roldan, J. L. (2010), “Applying Maximum Likelihood and PLS on Different Sample Sizes: Studies on SERVQUAL Model and Employee Behaviour Model”. In V. Esposito Vinzi, W. W. Chin, J. Henseler \& H. Wang (Eds.), Handbook of Partial Least Squares: Concepts, Methods and Applications. Heidelberg: Springer. pp.427-447. http://dx.doi.org/ doi.org/10.1007/978-3-540-32827-8_20.

Beckhard, R. and Harris, R. (1987), "Organizational transitions", Reading, MA: AddisonWesley. http://dx.doi.org/ doi.org/10.1177/105960117700200422.

Bock, G., Zmud, R., Kim, Y. and Lee, J. (2005), "Behavioral intention formation in knowledge sharing: examining the roles of extrinsic motivators, social-psychological forces, and organizational climate", MIS Quarterly, Vol. 29 No. 1, pp. 87-111. http://dx.doi.org/ $10.2307 / 25148669$.

Boukes, M. (2019), "Social network sites and acquiring current affairs knowledge: The impact of Twitter and Facebook usage on learning about the news", Journal of Information 
Technology \& Politics, Vol. 16 No.1, pp.36-51. http://dx.doi.org/10.1080/19331681. 2019.1572568.

Bughin, J. and Chui, M. (2013), "Evolution of the networked enterprise: McKinsey Global Survey results", Available at: https://www.nextlearning.nl/wp-content/uploads/sites/ 11/2015/02/McKinsey-on-Impact-social-technologies.pdf

Carlson, J., Gudergan, S., Gelhard, C. and Rahman, M. (2019), "Customer engagement with brands in social media platforms: Configurations, equifinality and sharing", European Journal of Marketing, Vol. 53 No. 9, pp. 1733-1758. https://doi.org/10.1108/EJM-102017-0741.

Casimir, G., Lee, K. and Loon, M. (2012), "Knowledge sharing: influences of trust, commitment and cost", Journal of Knowledge Management, Vol. 16 No. 5, pp. 740-753. https://doi.org/10.1108/13673271211262781.

Chang, S-F and Chuang, M-H. (2012), "Factors that affect self-care behaviour of female high school students with dysmenorrhea: A cluster sampling study", International Journal of Nursing Practice, Vol. 18, pp. 117-124. http://dx.doi.org/ 10.1111/j.1440-172X.2012. 02007.x.

Chang, Y.-S. and Yang, C. (2013), "Why do we blog? From the perspectives of technology acceptance and media choice factors", Behaviour \& Information Technology, Vol. 32 No. 4, pp. 371-386. http://dx.doi.org/10.1080/0144929x.2012.656326.

Charband, Y. and Jafari Navimipour, N. (2018), "Knowledge sharing mechanisms in the education: A systematic review of the state of the art literature and recommendations for future research", Kybernetes, Vol. 47 No. 7, pp. 1456-1490. https://doi.org/10.1108/K06-2017-0227

Chatterjee, S., Ghosh, S.K. and Chaudhuri, R. (2020), "Knowledge management in improving business process: an interpretative framework for successful implementation of AICRM-KM system in organizations", Business Process Management Journal, Early Cite, https://doi.org/10.1108/BPMJ-05-2019-0183.

Chen, C.J., and Hung, S.W. (2010), "To give or to receive? Factors influencing members' knowledge sharing and community promotion in professional virtual communities", Information and Management, Vol. 47, pp. 226-236. https://doi.org/ 10.1016/ j.im.2010. 03.001.

Chiang, C.-F. and Jang, S.C., (2008), "An expectancy theory model for hotel employee motivation”, Journal of Hospitality Management, Vol. 27 No. 2, pp. 313-322. https://doi.org/10.1016/j.ijhm.2007.07.017.

Chieng, C.F., and Soocheng, J. (2008), "An expectancy theory model for hotel employee innovation", Journal of Hospitality Management, Vol. 27 No. 2, pp. 313-322. http://dx.doi.org/ 10.1016/ j. ijhm.2007.07.017.

Chin WW. (2003), PLS-Graph 3.0. Houston: Soft Modeling Inc.

Chong, C.W., Yuen, Y.Y. and Gan, G.C. (2014), "Knowledge sharing of academic staff", Library Review, Vol. 63 No. 3, pp. 203-223. http://dx.doi.org/10.1108/LR-08-20130109.

Cohen, J., and Cohen, P. (1983), Applied multiple regression correlation analysis for the behavioral science, $2^{\text {nd }}$ Edition. Hillsdale, NJ, Erlbaum.

Condrey, S.E. (2005), "Motivating Personnel at Russian Nuclear Power Plants: A Case-Study of Motivation Theory Application", Public personnel management, Vol. 34 No. 4, pp. 343-356. https://doi.org/10.1177/009102600503400406.

Davenport, H. T. and Prusak, L. (1998). "Working knowledge: How organizations manage what they know", Cambridge, MA: Harvard Business School Press. http://dx.doi.org/ doi.org/10.1145/348772.348775. 
Deci, E., \& Ryan, R. (2000). Intrinsic and Extrinsic Motivations: Classic Definitions and New Directions. Contemporary Educational Psychology, 25, 54-67. https://doi.org/10.1006/ ceps.1999.1020.

Della Peruta, M.R., Campanella, F., and Giudice, M.D. (2014), "Knowledge sharing and exchange of information within bank and firm networks: the role of the intangibles on the access to credit", Journal of Knowledge Management, Vol. 18 No. 5, pp. 1036 1051. https://doi.org/10.1108/JKM-06-2014-0255.

Felin, T. and Hesterly, W.S. (2007), "The knowledge-based view, nested heterogeneity, and new value creation: Philosophical considerations on the locus of knowledge." Academy of Management Review, Vol. 32 No. 1, pp. 195-218. http://dx.doi.org/10.2307/20159288.

Fornell, C., \& Larcker, D. F. (1981), "Evaluating structural equation models with unobservable variables and measurement error", Journal of Marketing Research, Vol. 18 No. 1, pp. 39-50. http://dx.doi.org/ 10.2307/3151312.

Fullwood, R., Rowley, J. and Delbridge, R. (2013), "Knowledge sharing amongst academics in UK universities", Journal of Knowledge Management, Vol. 17 No. 1, pp. 123-136. http://dx.doi.org/ 10.1108/13673271311300831.

Gefen, D. (2000), "E-commerce: The role of familiarity and trust", The International Journal of Management Science, Vol. 28 No. 6, pp. 725-737. https://doi.org/10.1016/S03050483(00)00021-9.

Giudice, M.D., and Della Peruta, M.R. (2016), "The impact of IT-based Knowledge Management Systems on internal venturing and innovation: a Structural Equation Modeling approach to corporate performance", Journal of Knowledge Management, Vol. 20 No. 3, pp. 484-498. https://doi.org/10.1108/JKM-07-2015-0257.

Giudice, M.D., Carayannis, E.G., and Della Peruta, M.R. (2012), Cross-Cultural Knowledge Management, In handbook of Fostering Innovation and Collaboration, Inside the Multicultural Enterprise, Springer Publication. http://dx.doi.org/10.1007/978-1-46142089-7.

Giunchiglia, F., Zen, M., Gobbi, E., Bignotti, E., \& Bison, I. (2018). Mobile social media usage and academic performance. Computers in Human Behavior, 82, 177-185. https://doi.org/10.1016/j.chb.2017.12.041

Goh, S.K. and Sandhu, M.S. (2013), "Knowledge sharing among Malaysian academics: Influence of affective commitment and trust", Electronic Journal of Knowledge Management, Vol. 11 No. 1, pp. 38-48.

Goswami, A.K. and Agrawal, R.K. (2019), "Explicating the influence of shared goals and hope on knowledge sharing and knowledge creation in an emerging economic context", Journal of Knowledge Management, Vol. 24 No. 2, pp. 172-195. https://doi.org/10.1108/JKM-09-2018-0561.

Grace, T. P. L. (2009), "Wikis as a knowledge management tool", Journal of Knowledge Management, Vol. 13 No. 4, pp. 64-74. http://dx.doi.org/10.1108/13673270910971833.

Haas, M.R. and Hansen, M.T. (2005), "When Using Knowledge Can Hurt Performance: The Value of Organizational Capabilities in a Management Consulting Company", Strategic Management Journal, Vol. 26 No. 1, pp. 1-24. http://dx.doi.org/10.1002/smj.429.

Hair, J. F., Ringle, C.M. and Sarstedt, M. (2011), "PLS-SEM: Indeed, a Silver Bullet", Journal of Marketing Theory and Practice, Vol. 19 No. 2, pp. 139-152. http://dx.doi.org/10.2753/ MTP1069-6679190202.

Hair, J. F., Sarstedt, M., Ringle, C. M. and Gudergan, S. P. (2018), Advanced Issues in Partial Least Squares Structural Equation Modeling (PLS-SEM), Thousand Oaks, CA: Sage Publications. 
Hair, J., Anderson, R., Tatham, R., and Black, W. (1998), "Multivariate Data Analysis with Readings", New York, McMillan.

Henseler, J., Dijkstra, T. K., Sarstedt, M., Ringle, C. M., Diamantopoulos, A., Straub, D. W., and Calantone, R. J. (2014), "Common beliefs and reality about PLS: Comments on Rönkkö and Evermann”. Organizational Research Methods, Vol. 17 No. 2, pp. 182209. https://doi.org/10.1177/1094428114526928.

Hertel, G., Niedner, S., \& Herrmann, S. (2003). Motivation of software developers in open source projects: An Internet-based survey of contributors to the Linux kernel. Research Policy, 32, 1159-1177. http://dx.doi.org/10.1016/s0048-7333(03)00047-7.

Hofsted, G. (1997), "Culture and Organizations: Software of the mind", USA: McGraw-Hill Education, 3rd edition.

Howell, K., and Annansingh, F. (2013), "Knowledge Generation and Sharing in UK Universities: A Tale of Two Cultures?", International Journal of Information Management, Vol. 33 No. 1, pp. 32-39. http://dx.doi.org/ 10.1016/j.ijinfomgt.2012.05.003.

Hsu, M.H., Ju, T.L., Yen, C.H. \& Chang, C.M. (2007), "Knowledge Sharing Behavior in Virtual Communities: The Relationship Between Trust, Self-efficacy, and Outcome Expectations", International Journal of Human-Computer Studies, Vol. 65 No. 2, pp.153-69. https://doi.org/10.1016/j.ijhcs.2006.09.003.

Hu, L. -T., \& Bentler, P. M. (1999), "Cutoff criteria for fit indexes in covariance structure analysis: Conventional criteria versus new alternatives", Structural Equation Modeling, Vol. 6 No. 1, pp. 1-55. https://doi.org/10.1080/10705519909540118.

Iqbal, M.J., Rasli, A., Heng, L.H., Ali, M.B., Hassan, I. and Jolaee, A. (2011), “Academic staff knowledge sharing intentions and university innovation capability", African Journal of Business Management, Vol. 5 No. 27, pp. 11051-11059. http://dx.doi.org/10.5897/ AJBM11.576.

Jolaee, A., Md. Noor, K., Khani, N. and Md Yusoff, R. (2014), "Factors affecting knowledge sharing intention among academic staff", International Journal of Educational Management, Vol. 28 No. 4, pp. 413-431. http://dx.doi.org/10.1108/IJEM-03-20130041.

Kankanhalli, A., Tan, B. C. Y., and Wei, K. K. (2005), "Contributing knowledge to electronic repositories: an empirical investigation”, MIS Quarterly, Vol. 29 No. 1, pp. 113-143. http://dx.doi.org/10.2307/25148670.

Keppel, G., and Wickens, T.D. (2004), "Design and Analysis: A researcher's handbook", $4^{\text {th }}$ International Edition., Upper Saddle River, NJ, Pearson Prentice-Hall.

$\mathrm{Kim}, \mathrm{S}$. and $\mathrm{Ju}, \mathrm{B}$. (2008), "An analysis of faculty perceptions: attitudes toward knowledge sharing and collaboration in an academic institution", Library \& Information Science Research, Vol. 30 No. 4, pp. 282-290. http://dx.doi.org/10.1016/j.lisr.2008.04.003.

Kim, S. and Lee, H. (2006), "The Impact of organizational context and information technology on employee knowledge-sharing capabilities", Public Administration Review, pp. 370385. http://dx.doi.org/10.1111/j.1540-6210.2006.00595.x.

Latilla, V.M., Frattini,F., Petruzzelli, A.M., and Berner, M. (2018), "Knowledge management, knowledge transfer and organizational performance in the arts and crafts industry: a literature review", Journal of Knowledge Management, https://doi.org/10.1108/JKM08-2017-0367.

Lawler, E.E., and Suttle, J. L. (1973). "Expectancy theory and job behavior", Organizational Behavior and Human Performance, Vol. 9 No. 3, p. 482. https://doi.org/10.1016/00305073(73) 90066-4. 
Li, X. (2011), "Factors influencing the willingness to contribute information to online communities", New Media \& Society, Vol. 13 No. 2, pp. 279-296. http://dx.doi.org/10.1177/ 1461444810372164.

Linzalone, R., Schiuma, G. and Ammirato, S. (2020), "Connecting universities with entrepreneurship through digital learning platform: functional requirements and education-based knowledge exchange activities", International Journal of Entrepreneurial Behavior \& Research, Early cite. https://doi.org/10.1108/IJEBR-072019-0434.

Ma, W.W.K. and Chan, A. (2014), "Knowledge sharing and social media: altruism, perceived online attachment motivation, and perceived online relationship commitment", Computers in Human Behaviour, Vol. 39, pp. 51-58. http://dx.doi.org/ 10.1016/ j.chb.2014.06.015.

McGowan, B. S., Wasko, M., Vartabedian, B., Miller, R. S., Freiherr, D. D. and Abdolrasulnia, M. (2012), "Understanding the factors that influence the adoption and meaningful use of social media by physicians to share medical information", Journal of Medical Internet Research, Vol. 14 No. 5, pp. 210-220. http://dx.doi.org/10.2196/jmir.2138.

Mishra, A., Maheswarappa, S.S., Maitya, M., and Samu, S. (2018), "Adolescent's eWOM intentions: An investigation into the roles of peers, the Internet and gender", Journal of Business Research, Vol. 86 No. 5, pp. 394-405. https://doi.org/10.1016/j.jbusres. 2017.04.005.

Moeser, G., Moryson, H., \& Schwenk, G. (2013), "Determinants of online social business network usage behavior - applying the technology acceptance model and its extensions", Psychology, Vol. 4 No. 4, pp. 433-437. http://dx.doi.org/10.4236/psych.2013.44061.

Moskaliuk, J. and Kimmerle, J. (2009), "Using wikis for organizational learning: functional and psycho-social principles", Development and Learning in Organizations, Vol. 23 No. 4, pp. 21-24. http://dx.doi.org/10.1108/14777280910970756.

Nielsen, P., and Razmerita, L. (2014), Motivation and Knowledge Sharing through Social Media within Danish Organizations, Creating Value for All Through IT : IFIP WG 8.6 International Conference on Transfer and Diffusion of IT, TDIT 2014, Aalborg, Denmark, June 2-4, 2014 (pp.197-213). https://doi.org/10.1007/978-3-662-434598_13.

Nistor, N. (2014), “When technology acceptance models won't work: Non-significant intention-behavior effects", Computers in Human Behavior, Vol. 34, pp. 299-300. http://dx.doi.org/10.1016/j.chb.2014.02.052.

O'Leary, K. and Murphy, S. (2019), "Moving beyond Goffman: the performativity of anonymity on SNS", European Journal of Marketing, Vol. 53 No. 1, pp. 83-107. https://doi.org/10.1108/EJM-01-2017-0016.

Osatuyi, B. (2013), "Information sharing on social media sites", Computers in Human Behavior, Vol. 29 No. 6, pp. 2622-2631. http://dx.doi.org/10.1016/j.chb.2013.07.001.

Park, S.Y., Nam, M.-W. and Seung-Bong, C. (2012), "University students' behavioral intention to use mobile learning: evaluating the technology acceptance model", British Journal of Educational Technology, Vol.43 No.4, pp. 592-605. https://doi.org/10.1111/j.14678535.2011.01229.x

Park, Y. (2011), “A pedagogical framework for mobile learning: categorizing educational applications of mobile technologies into four types", International Review of Research in Open and Distance Learning, Vol. 12 No. 2, pp. 78-102. https://doi.org/ 10.3394/0380-1330(2006)32. 
Paroutis, S. and Al Saleh, A. (2009), "Determinants of knowledge sharing using Web 2.0 technologies", Journal of Knowledge Management, Vol. 13 No. 4, pp. 52-63. https://doi.org/10.1108/13673270910971824.

Pfisterer, S., Streim, A., \& Hampe, K. (2013), “Arbeit 3.0. Arbeiten in der digitalen Welt". Available at: http://www.bitkom.org/files/documents/Studie_Arbeit_3.0.pdf

Pinho, J.C.M.R., and Soares, A.M. (2011), "Examining the technology acceptance model in the adoption of social networks", Journal of Research in Interactive Marketing, Vol. 5 No. (2/3), pp. 116-129. http://dx.doi.org/10.1108/17505931111187767.

Pirkkalainen, H., and Pawlowski, J. M. (2014), "Global social knowledge management understanding barriers for global workers utilizing social software", Computers in Human Behavior, Vol. 30, pp. 637-647. http://dx.doi.org/10.1016/j.chb.2013.07.041.

Preece, J. and Shneiderman, B. (2009), "The reader-to-leader framework: Motivating technology-mediated social participation", AIS Transactions on Human-Computer Interaction, Vol. 1 No. 1, pp. 13-32. Available at: http://aisel.aisnet.org/thci/vol1/iss1/5.

Rahmi, D.Y. and Indarti, N. (2019), "Examining the relationships among cognitive diversity, knowledge sharing and team climate in team innovation", Team Performance Management, Vol. 25 No. 5/6, pp. 299-317. https://doi.org/10.1108/TPM-11-20180070.

Ramayah, T., Yeap, J.A.L. and Ignatius, J. (2013), “An empirical inquiry on knowledge sharing among academicians in higher learning institutions", Minerva, Vol. 51 No. 2, pp. 131154. http://dx.doi.org/10.1007/s11024-013-9229-7.

Razmerita, L., Kirchner, K., \& Nabeth, T. (2014), “Social Media In Organizations: Leveraging Personal And Collective Knowledge Processes", Journal of Organizational Computing and Electronic Commerce, Vol. 24 No.1, pp. 74-93. https://doi.org/10.1080/10919392. 2014.866504.

Read, W., Robertson, N., McQuilken, L. and Ferdous, A. (2019), "Consumer engagement on Twitter: perceptions of the brand matter", European Journal of Marketing, Vol. 53 No. 9, pp. 1905-1933. https://doi.org/10.1108/EJM-10-2017-0772

Reagans, R. and McEvly, B. (2003), "Network Structure and Knowledge Transfer: The Effects of Cohesion and Range" Administrative Science Quarterly, Vol. 48 No. 2, pp. 240-267. https://doi.org/10.2307/3556658.

Ringle CM, Sarstedt M, Mitchell R, et al. (2019), Partial Least Squares Structural Equation Modeling in HRM Research. The International Journal of Human Resource Management. Vol. 31 No. 12, pp. 1617-1643. https://doi.org/10.1080/09585192.2017. 1416655.

Ringle CM, Wende S and Becker J-M. (2015) SmartPLS 3. Bönningstedt: SmartPLS.

Seitz, S.R. and Misra, K. (2020), "Knowledge sharing in social networks: considering the role of political skill and trust", International Journal of Organization Theory \& Behavior, Vol. 23 No. 2, pp. 121-140. https://doi.org/10.1108/IJOTB-07-2019-0091.

Shmueli, G., Sarstedt, M., Hair, J., Cheah, J., Ting, H., Vaithilingam, S. and Ringle, C. (2019), "Predictive model assessment in PLS-SEM: guidelines for using PLSpredict", European Journal of Marketing, Vol. 53 No. 11, pp. 2322-2347. https://doi.org/10.1108/EJM-022019-0189.

Snead, K. C., \& Harrell, A. M. (1994), “An application of expectancy theory to explain a manager's intention to use a decision support system", Decision Sciences, Vol. 25 No. 4, pp. 499-513. http://dx.doi.org/10.1111/j.1540-5915.1994.tb01857.x.

Sosik J.J, Kahai S.S. and Piovoso M.J. (2009), Silver bullet or voodoo statistics? A primer for using the partial least squares data analytic technique in group and organization research. 
Group \& Organization Management, Vol. 34 No. 1, pp. 5-36. https://doi.org/10.1177/ 1059601108329198.

Stantchev, V., Colomo-Palacios, R., Soto-Acosta, P. and Misra, S. (2014), "Learning management systems and cloud file hosting services: A study on students' acceptance", Computers in Human Behavior, Vol. 31, pp. 612-619. http://dx.doi.org/10.1016 /j.chb.2013.07.002.

Sugathan, P., Rossmann, A. and Ranjan, K. (2018), "Toward a conceptualization of perceived complaint handling quality in social media and traditional service channels", European Journal of Marketing, Vol. 52 No. 5/6, pp. 973-1006. https://doi.org/10.1108/EJM-042016-0228.

Šumak, B., Heric `ko, M. and Pušnik, M. (2011), "A meta-analysis of e-learning technology acceptance: The role of user types and e-learning technology types", Computers in Human Behavior, Vol. 27 No. 6, pp. 2067-2077. http://dx.doi.org/10.1016/ j.chb.2011.08.005.

Sutanto, J. and Jiang, Q. (2013), “Knowledge seekers' and contributors' reactions to recommendation mechanisms in knowledge management systems", Information \& Management, Vol. 50, pp. 258-263. https://doi.org/10.1016/j.im.2012.11.004.

Tan, C.N.-L. and Md. Noor, S. (2013), "Knowledge management enablers, knowledge sharing and research collaboration: a study of knowledge management at research universities in Malaysia", Asian Journal of Technology Innovation, Vol. 21 No. 2, pp. 251-276. http://dx.doi.org/10.1080/19761597.2013.866314.

Urbach, N., and Ahlemann, F. (2010), "Structural Equation Modeling in Information Systems Research Using Partial Least Squares", Journal of Information Technology Theory and Application, Vol. 11 No. 2, pp. 5-40. Available at: http://aisel.aisnet.org/ jitta/vol11/ iss $2 / 2$.

Venkatesh, V. and Davis, F. D. (2000), "A theoretical extension of the technology acceptance model: Four longitudinal field studies", Management Science, Vol. 46 No. 2, pp. 186204. http://dx.doi.org/10.1287/mnsc.46.2.186.11926.

Venkatesh, V., Morris, M. G., Davis, G. B. and Davis, F. D. (2003), "User acceptance of information technology: Toward a unified view", MIS Quarterly, Vol. 27 No. 3, pp. 425-478. http://dx.doi.org/ 10.2307/30036540.

Venkitachalam, K. and Busch, P. (2012), "Tacit knowledge: review and possible research directions", Journal of Knowledge Management, Vol. 16 No. 2, pp. 356-371. http://dx.doi.org/ 10.1108/13673271211218915.

Vroom, V. H. (1964), "Work and motivation", New York: Wiley. http://garfield.library. upenn.edu/classics1985/A1985AKX9100001.pdf.

Weiger, W., Wetzel, H. and Hammerschmidt, M. (2019), "Who's pulling the strings? The motivational paths from marketer actions to user engagement in social media", European Journal of Marketing, Vol. 53 No. 9, pp. 1808-1832. https://doi.org/10.1108/EJM-10-2017-0777.

Whittington R. (2012), "Big strategy/small strategy" Strategic Organization, Vol. 10 No. 3, p. 263. http://dx.doi.org/ 10.1177/1476127012452828.

Yates, D. and Paquette, S. (2011), "Emergency knowledge management and social media technologies: a case study of the 2010 Haitian earthquake", International Journal of Information Management, Vol. 31 No. 1, pp. 6-13. http://dx.doi.org/10.1016/j.ijinfomgt. 2010.10.001.

Yi, Z. (2019), "A leader's approaches to fostering a culture of knowledge sharing in an information organization", Library Management, Vol. 40 No. 8/9, pp. 593-600. https://doi.org/10.1108/LM-11-2018-0083. 
Yong, L., Hongxiu, L. and Carlsson, C. (2010), "Factors driving the adoption of m-learning: an empirical study", Computers \& Education, Vol. 55 No. 3, pp. 1211-1219. https://doi.org/10.1016/j.compedu.2010.05.018.

Yoo, S. J., Han, S. and Huang, W. (2012), "The roles of intrinsic motivators and extrinsic motivators in promoting e-learning in the workplace: A case from South Korea", Computers in Human Behavior, Vol. 28 No. 3, pp. 942-950. http://dx.doi.org/10.1016/j.chb.2011.12.015.

Yu, T.-K., Lu, L.-C. and Liu, T.-F. (2010), "Exploring factors that influence knowledge sharing behavior via weblogs", Computers in Human Behavior, Vol. 26 No. 1, pp. 32-41. http://dx.doi.org/10.1016/j.chb.2009.08.002.

Appendix: Sample questionnaire

\begin{tabular}{llc}
\hline Items & Statement & $\begin{array}{c}\text { Response } \\
{[\mathrm{SD}][\mathrm{D}][\mathrm{N}][\mathrm{A}][\mathrm{SA}]}\end{array}$ \\
\hline IKE1 & Knowledge exchange is important & {$[1][2][3][4][5]$} \\
IKE2 & Knowledge exchange would improve the overall performance of institutions & {$[1][2][3][4][5]$} \\
IKE3 & Knowledge exchange effectively strategizes the practices to achieve success & {$[1][2][3][4][5]$} \\
IKE4 & I can develop my knowledge by getting inputs through knowledge exchange & {$[1][2][3][4][5]$} \\
PUS1 & I like the idea of using social media for academic purposes & {$[1][2][3][4][5]$} \\
PUS2 & Social media helps me to acquire academic knowledge I need & {$[1][2][3][4][5]$} \\
PUS3 & Getting feedbacks, suggestions, assignments etc. using social media is useful & {$[1][2][3][4][5]$} \\
EUS1 & I can acquire adequate knowledge to use social media for academic purposes & {$[1][2][3][4][5]$} \\
EUS2 & My social media experience for knowledge sharing would help me a lot & {$[1][2][3][4][5]$} \\
EUS3 & My institution encourages me to use social media & {$[1][2][3][4][5]$} \\
EUS4 & Learning becomes easy by using social media & {$[1][2][3][4][5]$} \\
IUS1 & I intend to use social media for academic discussion & {$[1][2][3][4][5]$} \\
IUS2 & I intend to use social media for self-study purpose & {$[1][2][3][4][5]$} \\
IUS3 & I intend to use social media for group discussion & {$[1][2][3][4][5]$} \\
\hline
\end{tabular}

